Article

\title{
Another Look into the Relationship between Economic Growth, Carbon Emissions, Agriculture and Urbanization in Thailand: A Frequency Domain Analysis
}

\author{
Mário Nuno Mata ${ }^{1, * \mathbb{D}}$, Seun Damola Oladipupo ${ }^{2} \mathbb{D}$, Rjoub Husam ${ }^{3} \mathbb{D}$, Joaquim António Ferrão ${ }^{1}$, \\ Mehmet Altuntaş ${ }^{4}$, Jéssica Nunes Martins ${ }^{5}(\mathbb{D})$, Dervis Kirikkaleli ${ }^{6} \mathbb{D}$, Rui Miguel Dantas ${ }^{1}(\mathbb{D})$ and \\ António Morão Lourenço ${ }^{7}$
}

Citation: Mata, M.N.; Oladipupo, S.D.; Husam, R.; Ferrão, J.A.; Altuntaş, M.; Martins, J.N.; Kirikkaleli, D.; Dantas, R.M.; Lourenço, A.M. Another Look into the Relationship between Economic Growth, Carbon Emissions, Agriculture and Urbanization in Thailand: A Frequency Domain Analysis. Energies 2021, 14, 5132. https://doi.org/10.3390/en14165132

Academic Editor: Almas Heshmati

Received: 15 July 2021

Accepted: 16 August 2021

Published: 19 August 2021

Publisher's Note: MDPI stays neutral with regard to jurisdictional claims in published maps and institutional affiliations.

Copyright: (c) 2021 by the authors. Licensee MDPI, Basel, Switzerland. This article is an open access article distributed under the terms and conditions of the Creative Commons Attribution (CC BY) license (https:// creativecommons.org/licenses/by/ $4.0 /)$.
1 ISCAL-Instituto Superior de Contabilidade e Administração de Lisboa, Instituto Politécnico de Lisboa, Avenida Miguel Bombarda 20, 1069-035 Lisbon, Portugal; jaferrao@iscal.ipl.pt (J.A.F.); rmdantas@iscal.ipl.pt (R.M.D.)

2 Department of Earth Science, Faculty of Science, Olabisi Onabanjo University, Ago-Iwoye 110262, Ogun State, Nigeria; seunlad50@gmail.com

3 Department of Accounting and Finance, Faculty of Economics and Administrative Sciences, Cyprus International University, Mersin 10, Haspolat 99040, Turkey; hrjoub@ciu.edu.tr

4 Department of Economics, Administrative and Social Sciences, Faculty of Economics, Nisantasi University, Istanbul 34398, Turkey; mehmet.altuntas@nisantasi.edu.tr

5 NOVA Information Management School (NOVA IMS), Universidade Nova de Lisboa, 1099-085 Lisbon, Portugal; jessicanunesmartins@gmail.com

6 Department of Banking and Finance, Faculty of Economics and Administrative Sciences, European University of Lefke, Northern Cyprus, TR-10, Mersin 99010, Turkey; dkirikkaleli@eul.edu.tr

7 Polytechnic Institute of Santarém, School of Management and Technology (ESGTS-IPS), 2001-904 Santarém, Portugal; antonio.lourenco@esg.ipsantarem.pt

* Correspondence: mnmata@iscal.ipl.pt

Abstract: This empirical study assesses the effect of $\mathrm{CO}_{2}$ emissions, urbanization, energy consumption, and agriculture on Thailand's economic growth using a dataset between 1970 and 2018. The ARDL and the frequency domain causality (FDC) approaches were applied to assess these interconnections. The outcome of the bounds test suggested a long-term association among the variables of investigation. The ARDL outcomes reveal that urbanization, agriculture, energy consumption, and $\mathrm{CO}_{2}$ emissions positively trigger Thailand's economic growth. Additionally, the frequency domain causality test was used to detect a causal connection between the series. The main benefit of this technique is that it can detect a causal connection between series at different frequencies. To the understanding of the authors, this is the first study in the case of Thailand that will apply the FDC approach to capture the causal linkage between GDP and the regressors. The outcomes of the causality test suggested that $\mathrm{CO}_{2}$ emissions, urbanization, energy consumption, and agriculture can predict Thailand's economic growth in the long term. These outcomes have far-reaching implications for economic performance and Thailand's macroeconomic indicators.

Keywords: agriculture; urbanization; economic growth; $\mathrm{CO}_{2}$ emissions; energy use; Thailand

\section{Introduction}

In most nations around the globe, sustainable economic development is the primary objective of economic policy [1,2]. Nevertheless, climate change and global warming are the key global challenges and problems that will affect economic development. Economic growth and civilization have led to increased carbon dioxide $\left(\mathrm{CO}_{2}\right)$ and other greenhouse gas (GHG) emissions [3-5]. There is a general opinion in the literature about how use of energy, $\mathrm{CO}_{2}$ pollution, and economic growth are related (GDP). In this regard, the level of $\mathrm{CO}_{2}$ emissions which mainly contribute to GHG emissions is determined by energy consumption and economic growth [6]. In many accounts, economic growth is identified 
as causing the catastrophic effects of pollution. Several economic activities aimed at economic development trigger emissions of $\mathrm{CO}_{2}$. In Thailand, since 2010, the consumption of energy per capita has been constant, at 2.1 toe in 2019 and at 2800 KWh per capita in 2019. Although energy consumption grew quickly overall between 2000 and 2013 (+4.7\%/year), it decreased dramatically from 2013 (+1\%/year) to 142 Mtoe in 2019. Oil, natural gas, biomass and coal, and lignite constitute $41 \%, 25 \%, 19 \%$ and $12 \%$ of the total primary energy of Thailand [7].

In the studies analyzing the determinants of economic growth, it seems that the effects of $\mathrm{CO}_{2}$ emissions [5,8-12], urbanization [12-14], energy consumption [14-16], and agriculture [17-19] have been examined. Nonetheless, their findings are mixed, leaving room for further study assessing the influence of agriculture, urbanization, energy use and economic growth on $\mathrm{CO}_{2}$ emissions. It is significant to mention that it is possible to explore the economy and provide adequate suggestions of economic sustainability based on empirical findings.

Why Thailand? Thailand has progressed significantly in terms of social and economic growth over the last four decades, shifting from a low-income nation to an upper-income nation in less than a generation. Thailand thus possesses a well-known successful development narrative with high sustained growth and a dramatic decline in poverty. In 2019, GDP and GDP Per Capita in Thailand stood at USD 543.5 billion and USD 7806.74, respectively $[19,20]$. The agriculture industry contributes to $9.9 \%$ of GDP in Thailand and comprises $49 \%$ of the workforce. The nation's economic development in the 1970s and the beginning of the 1980s was largely due to the constant expansion of the farming industry. Not only did the sector supply domestic food requirements, it also produced significant export surpluses of some commodities. Thailand depends heavily on the agriculture industry, with 20.4 million hectares of farmland (ESCAP). Rice is the main crop and Thailand is the largest rice exporting country in the world [21]. Other crops cultivated in the land include peanuts, sugar cane, fruit, medicinal plants, cassava, cassava, noodles, rubber, corn, cotton, cocoa, soya, and tobacco. Thailand's economy has been affected greatly recently as a result of stopping the tide of COVID-19, which has already resulted in significant employment losses, both in middle-class families and the disadvantaged, endangering hard-won gains in poverty alleviation. Economic growth had fallen in recent years from $4.2 \%$ in 2018 to $2.4 \%$ in 2019 [21]. Slowed growth was driven primarily by slower export demand, indicating the effect on agricultural output of tensions between the US and China, declining public investments and drought. Thailand's potential growth also presents key sustainability obstacles if it wishes to reach a high-income position by 2037 . These include poor schooling results and matching capabilities that pose risks for potential growth and opportunities of the younger generation and increased geographic deprivation and rural areas falling short of social and economic metrics [20]. Over the past 30 years, poverty had decreased significantly from $65.2 \%$ in 1988 to $9.85 \%$ in 2018 (based on official national estimates). In recent years, however, household revenue expansion and growth in demand have also slowed nationally. The number of people living in poverty in Thailand has been affected by that, which has reversed the poverty decline in Thailand.

Based on the aforementioned interesting characteristics of Thailand, the present research aims to assess the impact of $\mathrm{CO}_{2}$ emissions, agriculture, energy consumption and urbanization on economic growth in Thailand using yearly data from 1970 to 2018. To the best of the authors' understanding, no prior studies have been performed using these economic variables for the case of Thailand. Thus, the research fills a gap in the ongoing research by asking the fundamental questions: do $\mathrm{CO}_{2}$ emissions and agriculture trigger growth in Thailand? Do urbanization and energy consumption contribute to economic growth in Thailand?

The next segment presents a summary of associated studies. The data and methods are presented in Section 3, while the findings and discussion are illustrated in Section 4. The conclusion of the empirical analysis is presented in Section 5. 


\section{Theoretical Framework and Literature Review}

\subsection{Theoretical Framework}

Thailand's present economic policies are pro-growth; thus, ecological problems are taking a back seat on the policy platform. Continued expansion along this route will potentially ruin the economic growth trajectory. As a consequence, it is plausible to assume that Thailand's economic growth path may be traced back to the conventional growth-development trade-off argument. This debate is shown in a World Bank report on Thailand's environmental effect. The current study focuses on the health impacts on the workforce resulting from the environmental devastation caused by existing industrial practices. The OECD Global Forum on Environment revived this worry, identifying natural resource depletion and health concerns presented by exposure to air pollution as major economic obstacles. According to this discussion, Thailand's GDP growth will most probably be heavily dependent on $\mathrm{CO}_{2}$ emissions as a result of policy blindness, jeopardizing the foundations of sustainable development. At the same time, Thailand's economic growth is being driven by urban-centered industrial expansion. As industrial expansion and job opportunities expand in urban areas, citizens continue to migrate from rural areas to urban areas. Rapid urbanization generates demand for services and products, which promotes growth in the economy [22]. Higher demand for services and commodities requires increasing production, which involves increased energy use. As a result, economic growth is associated with an increase in energy consumption. Lastly, higher agricultural productivity stimulates economic expansion by boosting demand for (domestic) industry goods (Orhan et al., 2021). As a result, increased agricultural production is projected to stimulate economic expansion. The following is the theoretical research model based on the previous debates:

$$
\mathrm{GDP}_{\mathrm{t}}=\mathrm{f}\left(\mathrm{CO}_{2 \mathrm{t}}, \mathrm{URB}_{\mathrm{t}}, \mathrm{EC}_{\mathrm{t}}, \mathrm{AGRIC}_{\mathrm{t}}\right)
$$

where GDP represents economic growth, which is the dependent variable. The independent variables are $\mathrm{EC}, \mathrm{CO}_{2}, \mathrm{URB}$ and $\mathrm{EC}$, which represent use of energy, carbon emissions, urbanization, and agriculture, respectively, where $t$ indicates the period of study.

\subsection{Empirical Literature Review}

This portion of the empirical analysis discusses prior works conducted regarding the influence of $\mathrm{CO}_{2}$ emissions and agriculture on the economic growth of Thailand while also considering the role of urbanization and energy use. The findings indicate that there is no agreement on a clear result when it comes to the connection between environmental expansion and emissions; therefore, the research is somewhat open-ended. As a result, this topic has become more fascinating and has fostered additional contributions, allowing for a common ground to emerge. For instance, in Thailand, Ref. [23] assessed the comovement between $\mathrm{CO}_{2}$ and GDP using the novel wavelet and Toda-Yamamoto causality approaches and the empirical outcomes from this study unveiled positive coherency between $\mathrm{CO}_{2}$ and GDP, while the causality test unveiled one-way causality from GDP to $\mathrm{CO}_{2}$. Likewise, using Thailand, Ref. [24] investigated the interrelation between GDP and $\mathrm{CO}_{2}$ using data stretching from 1970 to 2010 employing the GMM approach. Their outcome indicated that an upsurge in $\mathrm{CO}_{2}$ was accompanied by an increase in GDP during the period of study. Similarly, Phrakhruopatnontakitti et al. (2020) scrutinized the influence of $\mathrm{CO}_{2}$ and energy consumption on GDP in Thailand, Singapore, Malaysia and Vietnam, and their empirical outcomes demonstrated that an upsurge in GDP could be attributed to an increase in energy use and $\mathrm{CO}_{2}$ emissions. Ref. [25] in their study on the GDP and $\mathrm{CO}_{2}$ connection in Thailand unveiled that an upsurge in $\mathrm{CO}_{2}$ contributed to economic expansion in Thailand. Similarly, the research of [19] reported a positive interrelation between $\mathrm{CO}_{2}$ and GDP, which implies that an increase in $\mathrm{CO}_{2}$ is associated with an increase in GDP in Thailand. Moreover, Ref. [26] assessed the $\mathrm{CO}_{2}-\mathrm{EC}-\mathrm{GDP}$ interconnection in Thailand using yearly data from 1970 to 2016. The investigators applied the ARDL, wavelet coherence and TY causality approaches. Their outcomes suggested that energy consumption and $\mathrm{CO}_{2}$ contribute to economic expansion in Thailand. 
Moreover, Ref. [27] looked into the association between economic growth and $\mathrm{CO}_{2}$ in Turkey using data spanning from 1968 to 2005. The investigators used time-series analyses to assess this association and their outcomes validate the EKC hypothesis. Furthermore, there is a positive association between GDP and $\mathrm{CO}_{2}$ in Turkey. The study of BalsalobreLorente et al. (2018) on the linkage between GDP and $\mathrm{CO}_{2}$ pollution in five EU nations established N-shaped interconnection between GDP and $\mathrm{CO}_{2}$. Additionally, Apergis and Ozturk (2015) assessed the GDP-CO $\mathrm{CO}_{2}$ connection using 14 Asian economies between 1990 and 2011. The authors applied the GMM approach to assess this connection and their outcome validates the EKC hypothesis in the selected countries. In Romania, the study reported in Ref. [28] established a positive linkage between GDP and $\mathrm{CO}_{2}$. Furthermore, studies reported in Ref. [29] for BRICST economies, Ref. [30] for Turkey, and Rehman et al. (2021) for Pakistan, as well as Dogan and Inglesi-Lotz (2020), validate the positive association between GDP and $\mathrm{CO}_{2}$.

Moreover, several studies have been conducted on the dynamic association between urbanization and GDP by numerous scholars. Nonetheless, their findings are mixed. For instance, using data spanning from 1971 to 2014, Ref. [31] assessed the connection between urbanization and GDP growth using DOLS and Granger causality test in Nigeria. The empirical outcomes suggested a positive urbanization-GDP connection, with causality running from urbanization to GDP. The study of [32] on the urbanization-GDP indicated that urban population triggers GDP. The positive GDP and urbanization association is consistent with the findings of [33] for ASEAN economies, and Zheng and Walsh (2019) for China, as well as [34] for India. Lastly, the association between agriculture and GDP has been assessed by several scholars with mixed outcomes. For instance, the study of [18] on the linkage between agriculture and GDP in Nigeria between 1981 and 2014 suggested that agriculture triggers GDP positively. The study of [35] in Brazil on the urbanization-growth association suggested that agriculture positively impacts GDP.

Based on the reviewed studies, there is no consensus on the association between economic growth and urbanization, agriculture, energy consumption and $\mathrm{CO}_{2}$ emissions. Thus, the present research assesses these connections by applying ARDL and the novel frequency domain causality (FDC) approaches. To the best of the authors' knowledge, this is the first study for the case of Thailand to use the FDC to capture the causal linkage between economic growth in Thailand and the independent variables at different frequencies.

\section{Data and Model}

\subsection{Data}

In this current research, yearly data stretching between 1970 and 2018 (49 observations) were used to capture the effect of agriculture and urbanization on GDP growth as well as take into account the influence of energy use and $\mathrm{CO}_{2}$ emissions in Thailand. The dependent variable is GDP, which represents economic growth and is measured as GDP per capita. The independent variables are EC, which is energy use calculated as energy consumption per capita, $\mathrm{CO}_{2}$ stands for carbon emissions, which are measured as emissions per capita, URB represents urbanization, which is measured as urban population, and AGRIC stands for agriculture, which is measured as agriculture, forestry and fishing, value added (constant 2010 US\$). The data for AGRIC, URB, GDP and URB were obtained from the World Bank database, while the data for $\mathrm{EC}$ and $\mathrm{CO}_{2}$ were gathered from the British petroleum database. Furthermore, to reduce skewness, we transformed all the data into their natural logarithm. A short description of the variables used is presented in Table 1. The mean of AGRIC, $\mathrm{CO}_{2}, \mathrm{EC}, \mathrm{GDP}$ and URB is 10.454, 0.2390, 3.8764, 3.4214 and 7.2518, respectively, with AGRIC having the highest mean. Moreover, the AGRIC ranges from 10.200 to $10.603, \mathrm{CO}_{2}$ ranges from -0.3800 to 0.6245 , $\mathrm{EC}$ ranges from 3.2589 to 4.3503, GDP ranges from 2.9680 to 3.8041, and URB ranges from 6.8867 to 7.5400 . All the variables are negative and moderately skewed since they are close to 0 . The kurtosis value suggested that all the series used are platykurtic since they are less than 3. Additionally, the Jarque-Bera suggested that only $\mathrm{CO}_{2}$ does not conform to normality with AGRIC, GDP, 
URB and EC conforming to normal distribution. Lastly, the correlation box, as depicted in Figure 1, shows evidence of positive correlation among GDP, URB, CO, EC and AGRIC, which implies that all the series move together in the same direction.

Table 1. Descriptive statistics.

\begin{tabular}{cccccc}
\hline Statistics & AGRIC & $\mathbf{C O}_{\mathbf{2}}$ & EC & GDP & URB \\
\hline Mean & 10.454 & 0.2390 & 3.8764 & 3.4214 & 7.2518 \\
Median & 10.471 & 0.3588 & 3.9792 & 3.5100 & 7.2485 \\
Maximum & 10.603 & 0.6245 & 4.3503 & 3.8041 & 7.5400 \\
Minimum & 10.200 & -0.3800 & 3.2589 & 2.9680 & 6.8867 \\
Std. Dev. & 0.1129 & 0.3253 & 0.3571 & 0.2663 & 0.1828 \\
Skewness & -0.5960 & -0.3384 & -0.2133 & -0.2792 & -0.1500 \\
Kurtosis & 2.3695 & 1.5547 & 1.5115 & 1.6839 & 2.1060 \\
Jarque-Bera & 3.7129 & 5.1996 & 4.8952 & 4.1730 & 1.8153 \\
Probability & 0.1562 & 0.0742 & 0.0864 & 0.1241 & 0.4034 \\
Observations & 49 & 49 & 49 & 49 & 49 \\
\hline
\end{tabular}

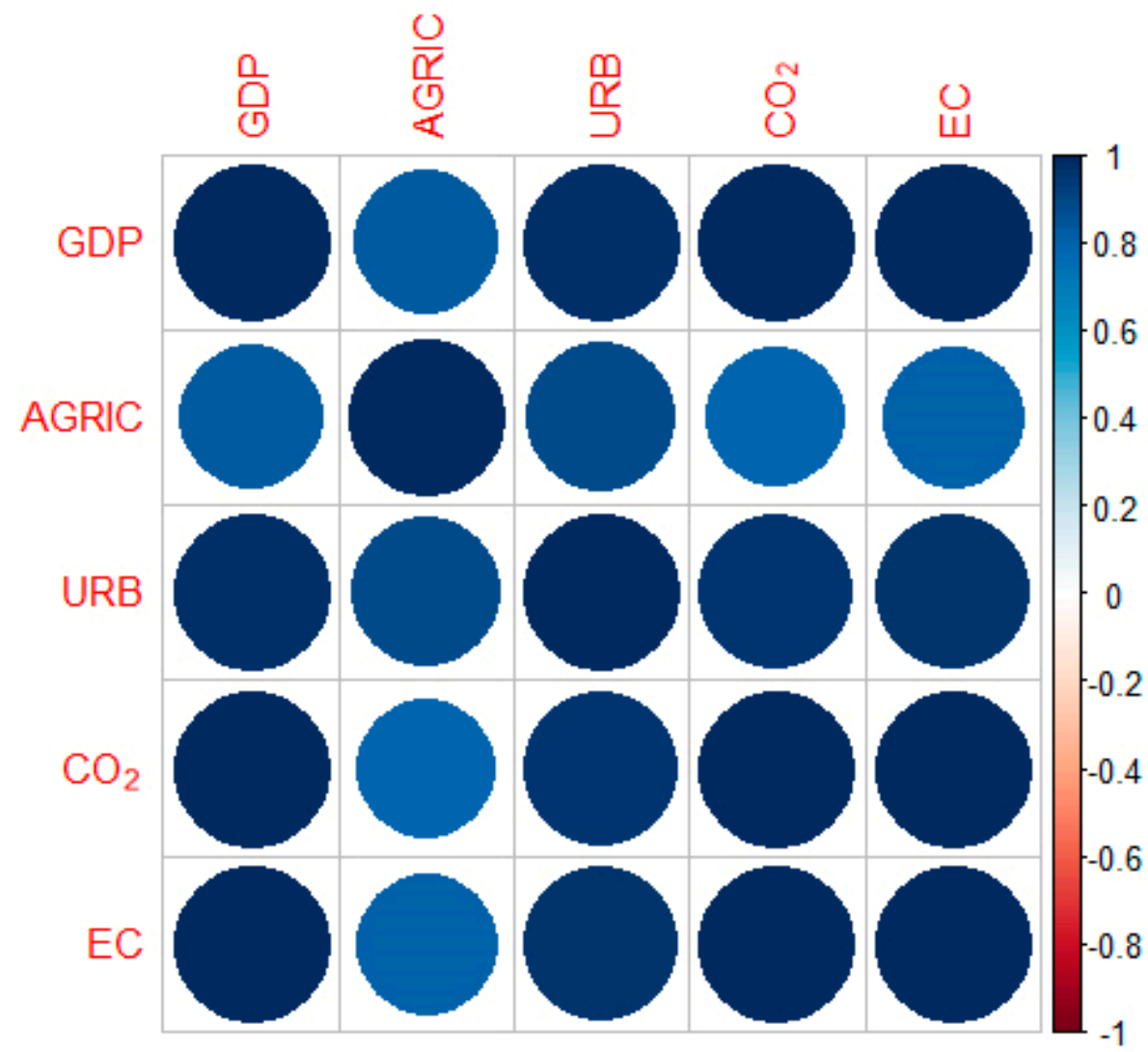

Figure 1. Correlation Box.

\subsection{Methodology}

\subsubsection{Stationarity Test}

Time series data are commonly considered to be most unstable, and the stationarity of the data must be tested for this purpose. A stationarity test is performed to check if the series is stable, as well as the order of integration by using some known estimating techniques such as ADF, PP and KPSS tests. The distinction between the PP and ADF tests is that the ADF considers heteroskedasticity and serial correlation into consideration the error term as a consequence of the incorporated dependent variable-lagged difference term, whereas the PP test corrects for heteroskedasticity and serial correlation using nonparametric statistical methods. As a result, the PP test may be regarded as an enhanced 
ADF. KPSS has been proven to have significantly more power than other traditional unit root tests (e.g., ADF and PP). The t-statistic testing technique is identical to the other two, but it varies in that the null hypothesis tests for no unit root, i.e., stationarity. As a result, the null hypothesis is rejected, indicating that the time series is nonstationary. It is also necessary to test the time series characteristics of the data by testing co-integration to allow precise modeling and decrease the chances of an inaccurate or erroneous estimate.

\subsubsection{ARDL Approach}

In addition, we found that the ARDL approach was suitable in this empirical analysis due to the small number [36]. Another explanation for the use of ARDL in the current study is its lag selection advantage, which offers an insight into the association between the series. This is always when the variables can be positive in one lag and negative in another lag. The ARDL approach also works perfectly well when the series have mixed integration orders, i.e., both I(1) and I(0). Therefore, in this analysis, we used the ARDL bounds test, which is illustrated as follows:

The econometric specification of ARDL equation can be written as follows:

$$
\mathrm{GDP}=\theta_{0}+\theta_{1} \mathrm{CO}_{2}+\theta_{2} \mathrm{EC}+\theta_{3} \mathrm{AGRIC}+\theta_{4} \mathrm{URB}+\epsilon
$$

where GDP, $\mathrm{CO}_{2}$. EC, AGRIC and URB stand for economic growth, $\mathrm{CO}_{2}$ emissions, energy use, agriculture and urbanization respectively. In addition, the error term is depicted by $\varepsilon$ and $\theta_{1}, \theta_{2}, \theta_{3}$ and $\theta_{4}$ represent the coefficient of the variable in the model. Equation (4) is extended from the ARDL dynamic equation to incorporate both the long-term (ARDLbound testing) and short-term (error correction tests) Equations. Equations (3) and (4) represent the two models (long-term and short-term), respectively.

$$
G D P_{t}=\theta_{0}+\theta_{1} C O_{2 t-1}+\theta_{2} E C_{t-1}+\theta_{3} A_{G R I C_{t-1}}+\theta_{4} U R B_{t-1}+\epsilon_{t}
$$

$$
\Delta G D P_{t}=\theta_{0}+\theta_{i} \sum_{i=1}^{n} G D P_{t-1} \theta_{j} \sum_{j=1}^{n} C O_{2 t-j}+\theta_{k} \sum_{k=1}^{n} E C_{t-k}+\theta_{n} \sum_{n=1}^{n} A G R I C_{t-n}+\theta_{p} \sum_{p=1}^{n} U R B_{t-p}+\varphi E C M_{t-1}+\epsilon_{t}
$$

where in Equation (3), $\theta_{0}, \theta_{1}, \theta_{2}, \theta_{3}$ and $\theta_{4}$, and, in Equation (4), $\theta_{0}, \theta_{I}, \theta_{J}, \theta_{K}, \theta_{N}$ and $\theta_{p}$ are the long-term coefficients, and the parameters in Equation (6) are the short-term coefficients. The first difference of the variables is denoted by $\Delta$ in Equation (4), whereas the speed of adjustment is depicted by $E C M_{t-1}$. Before estimating ARDL dynamic tests, it is critical to examine the long-term relationship between the variables of interest using the bound test method.

We used the ARDL-bounds test method for this reason. The following are the hypotheses for cointegration testing. The null hypothesis, which rejects the presence of cointegration in the model, is defined as follows:

$$
H_{0}: \theta_{0}=\theta_{I}=\theta_{j}=\theta_{k}=\theta_{N}=\theta_{p}=0
$$

While the alternative hypothesis, which opposes the idea of there being no cointegration, is expressed as follows:

$$
H_{1}: \theta_{0}=\theta_{I}=\theta_{j}=\theta_{k}=\theta_{N}=\theta_{p} \neq 0
$$

This procedure is put to the test by comparing the computed F- and T-statistics to the critical values of both limits (lower I(0) and higher I(0)). In calculating the bounds test, the Wald or F-test is used.

\subsubsection{Frequency Domain Causality Test}

The conventional linear regression shows the linear connection only, which may be negative or positive, between the chosen variables. It does not signify the direction of 
the connection between the variables chosen; in other words, it does not specify which indicators are accountable for the other indicators' responses. The connection between GDP and energy consumption may be affected by the causality from energy usage to economic growth, or vice versa. This kind of deduction cannot be derived from a linear regression alone. We used the frequency domain causality test proposed by [37] to examine the relationship between GDP and URB, EC, $\mathrm{CO}_{2}$ and AGRIC. The test reveals the degree of this exact variation, as opposed to the time-domain method, which illustrates the time series' variability. Furthermore, we can trace nonlinearity and causal cycles at both high and low frequencies using a frequency-domain approach. The main benefit of this technique is that causal relationship between series may be uncovered at different frequencies. The null and alternative hypotheses for FDC are that there is no causality and that there is causality, respectively.

\section{Findings}

This part discloses the empirical outcomes based on the methodology applied. We verify the likelihood of a unit root in the variables used in this empirical analysis before further analysis is conducted. The unit root tests applied are ADF, PP and KPSS. The outcomes of these stationarity tests are depicted in Table 2. The outcomes from these tests suggested that the series were integrated at a mixed level, paving the way for the estimation of ARDL. We proceeded to assess the long-term association among the series of studies by employing the ARDL bound test. The outcomes of the ARDL bounds test are depicted in Table 3. The outcomes suggested a long-term connection among the series. This illustrates that the null hypothesis of no cointegration cannot be accepted at a significance level of $1 \%$.

Table 2. ADF and PP.

\begin{tabular}{ccccccc}
\hline & \multicolumn{2}{c}{ ADF } & \multicolumn{2}{c}{ PP } & \multicolumn{2}{c}{ KPSS } \\
\hline Variables & $\mathrm{I}(0)$ & $\mathrm{I}(1)$ & $\mathrm{I}(0)$ & $\mathrm{I}(1)$ & $\mathrm{I}(0)$ & $\mathrm{I}(1)$ \\
AGRIC & -2.5543 & $-7.5662^{*}$ & -2.5038 & $-7.5662^{*}$ & $0.13822^{* * *}$ & 0.0705 \\
$\mathrm{CO}_{2}$ & -0.9918 & $-4.9112^{*}$ & -1.0028 & $-4.8930^{*}$ & $0.2426^{*}$ & 0.0738 \\
GDP & -1.7278 & $-4.2142^{*}$ & -1.3427 & $-4.2196^{*}$ & $0.2427^{*}$ & 0.0681 \\
EC & -1.0584 & $-4.4386^{*}$ & -0.8846 & $-4.4996^{*}$ & $0.2055^{* *}$ & 0.1065 \\
URB & $-3.7998^{* *}$ & -2.0368 & $-3.38422^{* *}$ & -1.8072 & $0.1455^{* * *}$ & $0.1916^{* *}$ \\
\hline Note: $^{*}$, $^{* *}$ and \\
\end{tabular}

Table 3. ARDL bounds Test.

\begin{tabular}{cccc}
\hline Model & Optimal Lag & F-Statistics & Cointegration \\
\hline GDP $=f\left(\right.$ AGRIC, $\left.\mathrm{CO}_{2}, \mathrm{EC}, \mathrm{URB}\right)$ & $(2,1,3,1,0)$ & $6.107^{*}$ & Yes \\
Level of Significance & L-B & U-B & \\
$1 \%$ & 3.54 & 5.02 & \\
$2.5 \%$ & 3.25 & 4.49 & \\
$5 \%$ & 2.84 & 4.20 & \\
$10 \%$ & 2.49 & 3.79 & \\
\hline
\end{tabular}

Note: $1 \%$ level of significance denoted as ${ }^{*}$. U-B denotes the upper bound while L-B denotes the lower bounds.

Since the long-term association among the series is confirmed in Table 3 above, we proceeded to assess the influence of urbanization, agriculture, energy usage and $\mathrm{CO}_{2}$ emissions on GDP. Table 4 presents the long-term and short-term outcomes of ARDL. The $\mathrm{R}^{2}$ is 0.98 , which suggests that the regressors (urbanization, agriculture, $\mathrm{CO}_{2}$ emissions and energy usage) were able to predict $98 \%$ of GDP. In the long term, the following outcomes were observed: 
Table 4. ARDL Results.

\begin{tabular}{|c|c|c|c|c|}
\hline Regressors & Coefficient & Std. Error & t-Statistic & Prob. \\
\hline \multicolumn{5}{|c|}{ Short-term Outcomes } \\
\hline AGRIC & $0.0232 *$ & 0.0278 & 0.8352 & 0.4094 \\
\hline $\mathrm{CO}_{2}$ & 0.1984 * & 0.0665 & 2.9836 & 0.0052 \\
\hline URB & 0.123 & 0.0798 & 1.5451 & 0.1316 \\
\hline EC & $0.3701 *$ & 0.0904 & 4.0931 & 0.0002 \\
\hline ECT & $-0.3728 *$ & 0.0638 & -5.8423 & 0.0000 \\
\hline \multicolumn{5}{|c|}{ Long-term Outcomes } \\
\hline AGRIC & $0.1071 *$ & 0.0358 & 2.9885 & 0.0052 \\
\hline $\mathrm{CO}_{2}$ & 0.1805 * & 0.0808 & 2.4561 & 0.0193 \\
\hline URB & 0.1274 * & 0.0699 & 1.8205 & 0.0775 \\
\hline EC & $0.3701 *$ & 0.1047 & 3.5326 & 0.0012 \\
\hline \multicolumn{2}{|c|}{$\mathrm{R}^{2}$} & \multicolumn{3}{|c|}{0.98} \\
\hline \multicolumn{2}{|c|}{$\operatorname{Adj} R^{2}$} & \multicolumn{3}{|c|}{0.97} \\
\hline \multicolumn{5}{|c|}{ Post Estimation Tests } \\
\hline \multicolumn{2}{|r|}{$\chi^{2} \mathrm{ARCH}$} & \multicolumn{3}{|c|}{$1.160(0.349)$} \\
\hline \multicolumn{2}{|r|}{$\chi^{2}$ RESET } & \multicolumn{3}{|c|}{$1.123(0.269)$} \\
\hline \multicolumn{2}{|r|}{$x^{2}$ Normality } & \multicolumn{3}{|c|}{$0.989(0.609)$} \\
\hline \multicolumn{2}{|r|}{$\chi^{2} \mathrm{LM}$} & \multicolumn{3}{|c|}{$0.181(0.834)$} \\
\hline
\end{tabular}

Note: ${ }^{*}, * *$ and ${ }^{* * *}$ depicts level of significance.

Agriculture impacts GDP positively in Thailand, suggesting that holding other factors constant, a $0.10 \%$ increase in GDP is due to a $1 \%$ upsurge in agriculture. This association is as expected because Thailand is the world's biggest exporter of rice. In 2014, exports of rice represented $1.3 \%$ of GDP. Approximately $9-10.5 \%$ of Thailand's GDP is generated from agricultural production in general. Exports of manufactured foods, including canned tuna, frozen shrimp and pineapples, are increasing. This outcome aligns with studies [12] in Indonesia and [38] Pakistan.

An increase in $\mathrm{CO}_{2}$ emissions triggers GDP growth in Thailand, suggesting that a $0.19 \%$ upsurge in GDP is due to a $1 \%$ upsurge in $\mathrm{CO}_{2}$ pollution when other indicators are held constant. This result implies that an upsurge in pollution leads to the growth of Thailand's economy. This illustrates that economic activity is propelled by pollution. As an emerging nation, Thailand is focused on achieving economic expansion, and little concern is given to the quality of the environment. This shows that Thailand is in the effect phase of the EKC hypothesis, which postulates that degradation of the environment and growth increase together. This outcome complies with the studies [3,22,26,35], who established positive $\mathrm{GDP}-\mathrm{CO}_{2}$ relationship.

Urbanization triggers GDP growth in Thailand. This suggests that a $0.12 \%$ upsurge in GDP results from a 1\% upsurge in urbanization. The study suggests that the rising population in Thailand is efficient in its economic trajectory. That being said, officials must be cautious in matching urban facilities and infrastructure in rural areas. This is necessary to prevent a rush to the urban cities, because government tends to create urban regions more than rural regions. Such facilities could otherwise be overrun, which in the long term could hinder growth. Furthermore, the promotion of PPP in the construction of infrastructure in other less urban areas is necessary to offset infrastructure deficits in rural and metropolitan areas. These outcomes are in agreement with the study of [14] for South Korea, Ref. [13] for India, and [12] for Indonesia 
A positive-growth connection was established. This demonstrates that keeping other factors constant, a $0.37 \%$ upsurge in GDP growth is caused by a $1 \%$ upsurge in energy use. These results show that the Thailand economy is powered by energy and cannot embark on conservative energy strategies. This outcome is consistent with the prior studies $[14,17,35]$, which suggested a positive energy-growth connection.

The post-estimation test conducted suggested that there is no proof of serial correlation in the model revealed by LM test. Furthermore, no specification was observed on the basis of the RESET test, and the residuals were normally distributed, as shown by the normality test. In addition, the null hypothesis of heteroskedasticity was dismissed. Both CUSUM and CUSUM of Square revealed model stability, as shown in Figure 2a,b, respectively. The adjustment speed, as revealed by ECT was observed to facilitate convergence in the long run between the parameters, and it must be negative. The ECT outcome is -0.37 suggesting a model capacity to see $37 \%$ adjustment speed to ascertain the long-term equilibrium resulting from the independent variables (URB, AGRIC, URB and EC).

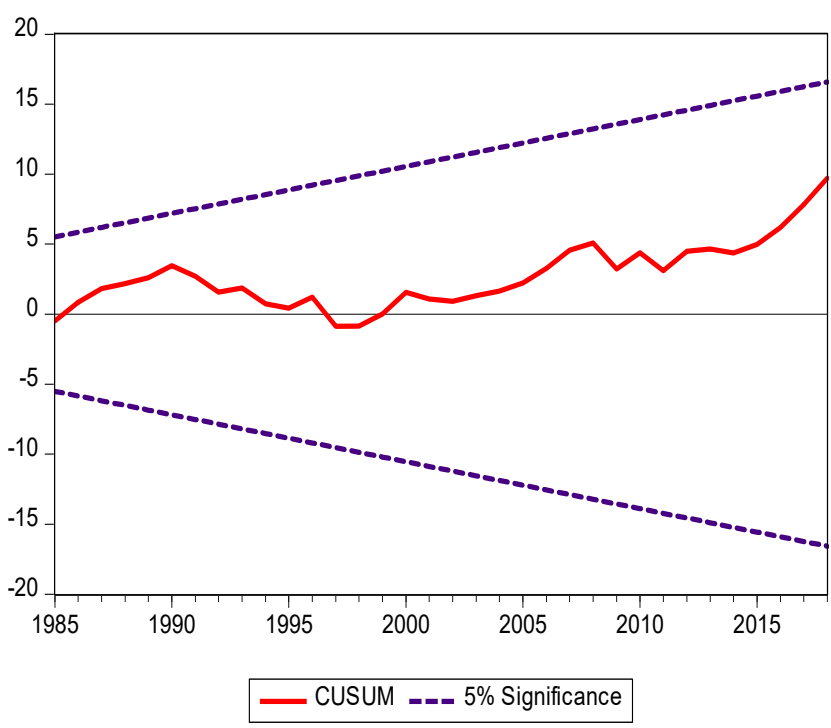

(a)

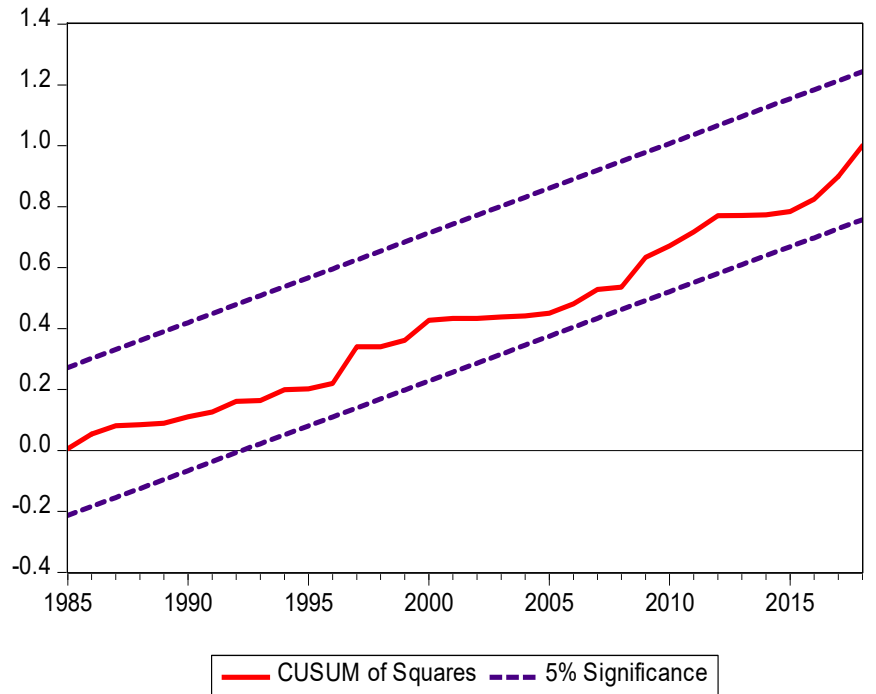

(b)

Figure 2. (a) CUSUM; (b) CUSUM Sq.

In a bid to establish the causal impact of EC, AGRIC, EC and $\mathrm{CO}_{2}$ on GDP in Thailand, the present study applied the frequency domain causality test. The outcomes of the test are presented in Table 5, and are as follows:

EC Granger causes increases in GDP in the short term, which implies that EC can predict GDP in Thailand in the short term. This shows that Thailand's economy is driven by fossil fuels. This outcome is consistent with the studies of [12] for Indonesia and [14] for South Korea, who established a one-way causality from EC to GDP. Urbanization Granger causes increases in GDP in the long term, which implies that GDP can be predicted by urbanization in Thailand in the long term. This will also have consequences for Thailand's economic progress in terms of rapid population growth, where spending will mostly be devoted to the population of poor masses in order to boost welfare. This outcome complies with the studies of $[17,31]$ for Nigeria.

Moreover, there is one-way causality from agriculture to GDP at all frequencies (short and long term), which demonstrates that AGRIC can predict GDP in Thailand in the long, medium and short term. These study outcomes comply with the works of $[18,19]$. There is a unidirectional causal linkage from $\mathrm{CO}_{2}$ to GDP in the long term which illustrates that $\mathrm{CO}_{2}$ can predict GDP in the long term. This study outcome complies with the works of $[39,40]$. 
Table 5. FDC test.

\begin{tabular}{ccccccc}
\hline & \multicolumn{2}{c}{ Long } & \multicolumn{2}{c}{ Medium } & \multicolumn{2}{c}{ Short } \\
\hline Direction of Causality & $\mathrm{w}_{\mathrm{i}}=0.01$ & $\mathrm{w}_{\mathrm{i}}=0.05$ & $\mathrm{w}_{\mathrm{i}}=1.00$ & $\mathrm{w}_{\mathrm{i}}=1.50$ & $\mathrm{w}_{\mathrm{i}}=2.00$ & $\mathrm{w}_{\mathrm{i}}=2.50$ \\
$\mathrm{EC} \rightarrow$ GDP & 1.1505 & 1.1480 & 0.2042 & 0.552 & $5.4922^{* * *}$ & $4.8038^{* * *}$ \\
$\mathrm{CO}_{2} \rightarrow$ GDP & $5.3252^{* * *}$ & $5.3295^{* * *}$ & 0.2216 & 1.5476 & 4.4211 & 3.0404 \\
$\mathrm{URB} \rightarrow$ GDP & $5.4656^{* * *}$ & $5.9731^{* * *}$ & 2.3531 & 0.1894 & 1.1179 & 1.2857 \\
$\mathrm{AGRIC} \rightarrow$ GDP & 3.1006 & $9.3211^{*}$ & $26.5467^{*}$ & $22.8541^{*}$ & $7.6647^{*}$ & 2.0097 \\
\hline
\end{tabular}

Note: *, and ${ }^{* * *}$ depicts level of significance of $1 \%$ and $10 \%$.

\section{Conclusions}

The present paper assesses the impact of agriculture and urbanization on Thailand's economic growth and considers the influence of $\mathrm{CO}_{2}$ emissions and energy use using data stretching between 1970 and 2018. To achieve the research objectives, the study applied ARDL and frequency domain causality approaches. To the best of the authors' knowledge, no prior studies have assessed this interconnection by employing the frequency domain causality test for the case of Thailand. Furthermore, the ARDL long estimate validates the positive energy-growth association, which implies that an upsurge in energy use causes increased GDP growth. This outcome complies with the studies of $[8,14,26,41,42]$, who established the positive energy-growth association. In addition, urbanization triggers economic expansion in Thailand, which is consistent with the studies of $[12,13,31]$. Moreover, $\mathrm{CO}_{2}$ emissions and agriculture contribute to economic expansion in Thailand. This outcome complies with studies $[24,43]$. Furthermore, $\mathrm{CO}_{2}$ emissions contribute to economic growth in Thailand. This outcome complies with the studies of [44-50]. Last, energy consumption triggers economic growth. This is not unexpected, given the fact that energy is needed for economic activities. The outcomes from the frequency domain causality test suggested that urbanization, $\mathrm{CO}_{2}$ emissions, agriculture and energy consumption can predict economic growth in Thailand. Thus, policy targeting urbanization, $\mathrm{CO}_{2}$ emissions, agriculture and energy consumption will have a significant impact on economic growth in Thailand.

The outcomes from this research allowed us to reach conclusions in agreement with those of the proponents of the diversification of Thailand's energy intensity. This result could be accomplished by implementing more ambitious clean energy source measures that would maintain the country's economic dynamism. The introduction and execution of good policies to regulate Thai energy and manufacturing sector practices will also strengthen the nation's sustainable development. Moreover, the government can also support regulating the nation's $\mathrm{CO}_{2}$ emission levels by imposing emissions controls on industrial firms and sectors. The alternative of leveling penalties or a high tax on infringers would deter environmental destruction. The incorporation of sustainable (renewable) energy sources, including hydro, oceanic energy and wind, should be considered. The introduction of these policies would help to sustain Thailand's strong economic development and environmental success.

In addition, the productivity of agriculture and its added value components can be improved at an increased pace without harming the ecosystem through the help of advanced agricultural technologies, the accessibility of high-quality seeds, and other agricultural inputs. The consequences and drawbacks of this research include the gains for-nearby nations and the duration of this research.

In addition, future studies should consider other determinants of economic growth and conduct similar studies using both develop and developing nations.

Author Contributions: Conceptualization, methodology, software, formal analysis, writing —original draft preparation, project administration, M.N.M., S.D.O., R.H., J.A.F., M.A., J.N.M., D.K. and A.M.L.; validation, resources, writing-review and editing, visualization, M.N.M., S.D.O., R.H., J.A.F., M.A., J.N.M., D.K., R.M.D. and A.M.L.; investigation, data curation, M.N.M., S.D.O., R.H., J.A.F., M.A., 
J.N.M. and D.K.; supervision, M.N.M., S.D.O., R.H., J.A.F., M.A., J.N.M., R.M.D. and A.M.L. All authors have read and agreed to the published version of the manuscript.

Funding: This research was supported by Instituto Politécnico de Lisboa.

Acknowledgments: We thank Instituto Politécnico de Lisboa for providing funding for this study.

Conflicts of Interest: The authors declare no conflict of interest.

\section{References}

1. Zhang, L.; Li, Z.; Kirikkaleli, D.; Adebayo, T.S.; Adeshola, I.; Akinsola, G.D. Modeling $\mathrm{CO}_{2}$ emissions in Malaysia: An application of Maki cointegration and wavelet coherence tests. Environ. Sci. Pollut. Res. 2021, 28, 26030-26044. [CrossRef]

2. Coelho, M.F.; Adebayo, T.S.; Onbaşığlu, D.Ç.; Rjoub, H.; Mata, M.N.; Carvalho, P.V.; Rita, J.X.; Adeshola, I. Modeling the Dynamic Linkage between Renewable Energy Consumption, Globalization, and Environmental Degradation in South Korea: Does Technological Innovation Matter? Energies 2021, 14, 4265. [CrossRef]

3. Adebayo, T.S.; Kirikkaleli, D. Impact of renewable energy consumption, globalization, and technological innovation on environmental degradation in Japan: Application of wavelet tools. Environ. Dev. Sustain. 2021. [CrossRef]

4. Agyekum, E.B.; Kumar, N.M.; Mehmood, U.; Panjwani, M.K.; Haes Alhelou, H.; Adebayo, T.S.; Al-Hinai, A. Decarbonize Russia-A Best-Worst Method approach for assessing the renewable energy potentials, opportunities and challenges. Energy Rep. 2021, 7, 4498-4515. [CrossRef]

5. Orhan, A.; Adebayo, T.S.; Genç, S.Y.; Kirikkaleli, D. Investigating the Linkage between Economic Growth and Environmental Sustainability in India: Do Agriculture and Trade Openness Matter? Sustainability 2021, 13, 4753. [CrossRef]

6. Udemba, E.N.; Adebayo, T.S.; Ahmed, Z.; Kirikkaleli, D. Determinants of consumption-based carbon emissions in Chile: An application of non-linear ARDL. Environ. Sci. Pollut. Res. 2021. [CrossRef]

7. Thailand Energy Information. 2021. Available online: https://www.enerdata.net/estore/energy-market/thailand.html (accessed on 23 May 2021).

8. Soylu, Ö.B.; Adebayo, T.S.; Kirikkaleli, D. The Imperativeness of Environmental Quality in China Amidst Renewable Energy Consumption and Trade Openness. Sustainability 2021, 13, 5054. [CrossRef]

9. Yuping, L.; Ramzan, M.; Xincheng, L.; Murshed, M.; Awosusi, A.A.; Bah, S.I.; Adebayo, T.S. Determinants of carbon emissions in Argentina: The roles of renewable energy consumption and globalization. Energy Rep. 2021, 7, 4747-4760. [CrossRef]

10. He, X.; Adebayo, T.S.; Kirikkaleli, D.; Umar, M. Consumption-based carbon emissions in Mexico: An analysis using the dual adjustment approach. Sustain. Prod. Consum. 2021, 27, 947-957. [CrossRef]

11. Tufail, M.; Song, L.; Adebayo, T.S.; Kirikkaleli, D.; Khan, S. Do fiscal decentralization and natural resources rent curb carbon emissions? Evidence from developed countries. Environ. Sci. Pollut. Res. 2021. [CrossRef]

12. Akinsola, G.D.; Adebayo, T.S.; Kirikkaleli, D.; Bekun, F.V.; Umarbeyli, S.; Osemeahon, O.S. Economic performance of Indonesia amidst $\mathrm{CO}_{2}$ emissions and agriculture: A time series analysis. Environ. Sci. Pollut. Res. 2021. [CrossRef]

13. Udemba, E.N.; Güngör, H.; Bekun, F.V.; Kirikkaleli, D. Economic performance of India amidst high $\mathrm{CO}_{2}$ emissions. Sustain. Prod. Consum. 2021, 27, 52-60. [CrossRef]

14. Adebayo, T.S.; Awosusi, A.A.; Kirikkaleli, D.; Akinsola, G.D.; Mwamba, M.N. Can $\mathrm{CO}_{2}$ emissions and energy consumption determine the economic performance of South Korea? A time series analysis. Environ. Sci. Pollut. Res. 2021, 28, 38969-38984. [CrossRef]

15. Leal, P.H.; Marques, A.C. The environmental impacts of globalisation and corruption: Evidence from a set of African countries. Environ. Sci. Policy 2021, 115, 116-124. [CrossRef]

16. Koengkan, M.; Fuinhas, J.A.; Auza, A. Measuring the effect of energy consumption on the epidemic of overweight in Latin America and Caribbean countries. Rev. Estud. Sociais 2021, 23. [CrossRef]

17. Udemba, E.N. Triangular nexus between foreign direct investment, international tourism, and energy consumption in the Chinese economy: Accounting for environmental quality. Environ. Sci. Pollut. Res. 2019, 26, 24819-24830. [CrossRef]

18. Matandare, M. Agriculture exports and economic growth in zimbabwe. Int. J. Soc. Sci. Econ. Res. 2017, $12,12-26$.

19. Bekun, F.V.; Agboola, M.O. Electricity Consumption and Economic Growth Nexus: Evidence from Maki Cointegration. Eng. Econ. 2019, 30, 14-23. [CrossRef]

20. World Bank. World Development Indicators. 2020. Available online: http://data.worldbank.org/country (accessed on 24 May 2021).

21. FAO. Key Stat Food Agric Extern Trade Food Agric Organ U N FAO. 2006. Available online: http://www.fao.org/es/ess/ toptrade / trade.asp?dir=exp\&country=3\&ryear=2004 (accessed on 29 May 2021).

22. Shan, S.; Ahmad, M.; Tan, Z.; Adebayo, T.S.; Man Li, R.Y.; Kirikkaleli, D. The role of energy prices and non-linear fiscal decentralization in limiting carbon emissions: Tracking environmental sustainability. Energy 2021, 234, 121243. [CrossRef]

23. Adebayo, T.S.; Akinsola, G.D. Investigating the Causal Linkage Among Economic Growth, Energy Consumption and $\mathrm{CO}_{2}$ Emissions in Thailand: An Application of the Wavelet Coherence Approach. Int. J. Renew. Energy Dev. 2021, 10, 17-26. [CrossRef]

24. Van Hoa, T.; Limskul, K. Economic impact of $\mathrm{CO}_{2}$ emissions on Thailand's growth and climate change mitigation policy: A modelling analysis. Econ. Model. 2013, 33, 651-658. [CrossRef] 
25. Boontome, P.; Therdyothin, A.; Chontanawat, J. Investigating the causal relationship between non-renewable and renewable energy consumption, $\mathrm{CO}_{2}$ emissions and economic growth in Thailand11This is a preliminary work. Please do not quote or cite without permission of the authors. Energy Procedia 2017, 138, 925-930. [CrossRef]

26. Odugbesan, J.A.; Adebayo, T.S.; Akinsola, G.D.; Olanrewaju, V.O. Determinants of Environmental Degradation in Thailand: Empirical Evidence from ARDL and Wavelet Coherence Approaches. Pollution 2021, 7, 181-196. [CrossRef]

27. Ozturk, I.; Acaravci, A. Energy consumption, $\mathrm{CO}_{2}$ emissions, economic growth, and foreign trade relationship in Cyprus and Malta. Energy Sour. Part B Econ. Plan. Policy 2016, 11, 321-327. [CrossRef]

28. Emir, F.; Bekun, F.V. Energy intensity, carbon emissions, renewable energy, and economic growth nexus: New insights from Romania. Energy Environ. 2019, 30, 427-443. [CrossRef]

29. Dogan, E.; Inglesi-Lotz, R. The impact of economic structure to the environmental Kuznets curve (EKC) hypothesis: Evidence from European countries. Environ. Sci. Pollut. Res. 2020, 27, 12717-12724. [CrossRef] [PubMed]

30. Kirikkaleli, D.; Adebayo, T.S.; Khan, Z.; Ali, S. Does globalization matter for ecological footprint in Turkey? Evidence from dual adjustment approach. Environ. Sci. Pollut. Res. 2021, 28, 14009-14017. [CrossRef]

31. Nathaniel, S.P.; Bekun, F.V. Environmental management amidst energy use, urbanization, trade openness, and deforestation: The Nigerian experience. J. Public Aff. 2020, 20, e2037. [CrossRef]

32. Nguyen, H.M.; Nguyen, L.D. The relationship between urbanization and economic growth: An empirical study on ASEAN countries. Int. J. Soc. Econ. 2018, 45, 316-339. [CrossRef]

33. Udi, J.; Bekun, F.V.; Adedoyin, F.F. Modeling the nexus between coal consumption, FDI inflow and economic expansion: Does industrialization matter in South Africa? Environ. Sci. Pollut. Res. Int. 2020, 27, 10553-10564. [CrossRef]

34. Yang, Z.; Zhao, Y. Energy consumption, carbon emissions, and economic growth in India: Evidence from directed acyclic graphs. Econ. Model. 2014, 38, 533-540. [CrossRef]

35. Awosusi, A.A.; Adebayo, T.S.; Odugbesan, J.A.; Akinsola, G.D.; Wong, W.-K.; Rjoub, H. Sustainability of Energy-Induced Growth Nexus in Brazil: Do Carbon Emissions and Urbanization Matter? Sustainability 2021, 13, 4371. [CrossRef]

36. Pesaran, M.H.; Shin, Y.; Smith, R.J. Bounds testing approaches to the analysis of level relationships. J. Appl. Econom. 2001, 16, 289-326. [CrossRef]

37. Breitung, J.; Candelon, B. Testing for short- and long-run causality: A frequency-domain approach. J. Econom. 2006, 132, 363-378. [CrossRef]

38. Udemba, E.N. Pakistan Ecological Footprint and Major Driving Forces, Could Foreign Direct Investment and Agriculture Be Among? In Assessment of Ecological Footprints; Muthu, S.S., Ed.; Springer: Singapore, 2021; pp. 109-122.

39. Apergis, N.; Payne, J.E. Renewable energy, output, $\mathrm{CO}_{2}$ emissions, and fossil fuel prices in Central America: Evidence from a nonlinear panel smooth transition vector error correction model. Energy Econ. 2014, 42, 226-232. [CrossRef]

40. Kihombo, S.; Ahmed, Z.; Chen, S.; Adebayo, T.S.; Kirikkaleli, D. Linking financial development, economic growth, and ecological footprint: What is the role of technological innovation? Environ. Sci. Pollut. Res. 2021. [CrossRef] [PubMed]

41. Kirikkaleli, D.; Adebayo, T.S. Do public-private partnerships in energy and renewable energy consumption matter for consumption-based carbon dioxide emissions in India? Environ. Sci. Pollut. Res. 2021, 28, 30139-30152. [CrossRef] [PubMed]

42. Kirikkaleli, D.; Adebayo, T.S. Do renewable energy consumption and financial development matter for environmental sustainability? New global evidence. Sustain. Dev. 2021, 29, 583-594. [CrossRef]

43. Phrakhruopatnontakitti, P.; Watthanabut, B.; Jermsittiparsert, K. Energy Consumption, Economic Growth and Environmental Degradation in 4 Asian Countries: Malaysia, Myanmar, Vietnam and Thailand. Int. J. Energy Econ. Policy 2020, 10, 529-539. [CrossRef]

44. Oladipupo, S.D.; Adebayo, T.S.; Awosusi, A.A.; Agyekum, E.B.; Jayakumar, A.; Kumar, N.M. Dominance of Fossil Fuels in Japan's National Energy Mix and Implications for Environmental Sustainability. Int. J. Environ. Res. Public Health 2021, $18,7347$.

45. Ramzan, M.; Iqbal, H.A.; Adebayo, T.S.; Awosusi, A.A.; Akinsola, G.D. The environmental sustainability effects of financial development and urbanization in Latin American countries. Environ. Sci. Pollut. Res. 2021, 8, 1-4.

46. Ayobamiji, A.A.; Kalmaz, D.B. Reinvestigating the determinants of environmental degradation in Nigeria. Int. J. Econ. Policy Emerg. Econ. 2020, 13, 52-71. [CrossRef]

47. Akinsola, G.D.; Adebayo, T.S.; Rjoub, H.; Oladipupo, S.D. The asymmetric effects of renewable energy consumption and trade openness on carbon emissions in Sweden: New evidence from quantile-on-quantile regression approach. Environ. Sci. Pollut. Res. 2021, 6, 1-2.

48. Lin, X.; Zhao, Y.; Ahmad, M.; Ahmed, Z.; Rjoub, H.; Adebayo, T.S. Linking Innovative Human Capital, Economic Growth, and $\mathrm{CO}_{2}$ Emissions: An Empirical Study Based on Chinese Provincial Panel Data. Int. J. Environ. Res. Public Health 2021, $18,8503$. [CrossRef]

49. Wang, K.H.; Liu, L.; Adebayo, T.S.; Lobon, O.R.; Claudia, M.N. Fiscal decentralization, political stability and resources curse hypothesis: A case of fiscal decentralized economies. Resour. Policy 2021, 1, 102071. [CrossRef]

50. Adeshola, I.; Adebayo, T.S.; Agboola, M.O.; Rjoub, H.; Agyekum, E.B.; Kumar, N.M. Linking Economic Growth, Urbanization, and Environmental Degradation in China: What Is the Role of Hydroelectricity Consumption? Int. J. Environ. Res. Public Health 2021, 18, 6975 . 